\title{
Awareness effects by aquapuncture with dexamethasone in tiletamine/zolazepam anesthetized dogs
}

\author{
Hyung-Jin Park, Kun-Ho Song*, Duck-Hwan Kim \\ College of Veterinary Medicine, Chungnam National University, Daejeon 305-764, Korea \\ (Received: October 10, 2011; Revised: December 06, 2011; Accepted: December 07, 2011)
}

\begin{abstract}
Awareness effect of aquapuncture with dexamethasone on GV-26 was studied in tiletamine/ zolazapam anesthetized six healthy crossbred dogs using a randomized cross-over experimental study design. After anesthesia by tiletamine/zolazapam, $0.1 \mathrm{mg}$ dexamethasone was injected on GV-26 at 20 $\mathrm{min}$ in the experimental group. For the control group, $0.1 \mathrm{mg}$ dexamethasone was injected on the quadriceps femoralis. A significant difference was evident in the sedation score between groups at 60 and $90 \mathrm{~min}(p<0.05)$. A significant difference was also evident in the analgesia score at 50 and 60 $\min (p<0.05)$. At $90 \mathrm{~min}$, all dogs in the experimental group responded strongly to pain $(p<0.01)$. Head up time, sternal recumbent time, standing time, and walking time was shorter in the experimental group, but the difference from the control group was statistically significant only for head up time and walking time $(p<0.05)$. GV-26 acupuncture with dexamethasone is useful for awareness effects after anesthesia.
\end{abstract}

Keywords : analgesia, aquapuncture, awareness, dog, GV-26, tiletamine/zolazapam

\section{Introduction}

Zoletil is a non-opioid, non-barbiturate, injectable anesthetic consisting of an equal mixture of tiletamine [2-(ethylamino)-2-(2-thienyl) cyclohexanone hydrochloride] (tiletamine $\mathrm{HCl}$ ) and zolazepam $\mathrm{HCl}$ [15]. Tiletamine $\mathrm{HCl}$, first reported in 1969 , is a dissociative anesthetic agent with pharmacologic properities similar to those of ketamine, but with a longer duration of action and greater analgesic effect than ketamine [11, 14]. Zolazepam[4-(o-fluorophenyl)-6, 8-dihydro-1,3,8-trimethylpyrzole[3,4-e]diazepine-7(1H)-one] is a benzodiazepine derivative with pharmacologic properities similar to those of diazepam [14]. Zolazepam induces muscle relaxation and tranquilization. Tiletamine quickly induces satisfactory levels of anesthesia, but has a short duration of anesthesia, poor muscle relaxation, and does not affect visceral pain. The tiletamine/zolazapam formulation marketed as Zoletil has proven to be a very useful drug for the induction of anesthesia in a wide variety of wild and domestic animals [6, 14]. There is no antidote for tiletamine-zolazepam, hence, there has been no standardized protocol to awaken deeply anesthetized animals.

Acupuncture is clinically effective in treatment of cardiovascular disease [16], musculoskeletal disease [1], and gastrointestinal disease [7]. Yet, little is known regarding the mechanism(s) of action. The cardiovascular effects of acupuncture include improvement of myocardial ischemia [16] and recovery from myocardial infarction [2]. GV-26, ST-9, ST-36, LI-11, KI-1, PC-6 can be used as acupoints for the cardiovascular system $[12,20]$. Good effectiveness of electroacupuncture on Jun Chung (GV-26) for awareness has been reported [10]. Aquapuncture is also one of the methods used in acupuncture treatment.

We designed this study to ascertain the effectiveness of aquapuncture with dexamethasone on GV-26 for awareness after tiletamine/zolazepam anesthesia.

\section{Materials and Methods}

\section{Animals}

Six crossbred dogs (2.9 4.1 kg of body weight) were

\footnotetext{
*Corresponding author

Tel: +82-42-821-6789, Fax: +82-42-821-6703

E-mail: songkh@cnu.ac.kr
} 
Table 1. Analgesia score in the dogs treated with Zoletil

\begin{tabular}{cl}
\hline \hline Score & \multicolumn{1}{c}{ Condition } \\
\hline 0 & Exaggerated movement of limbs and trying to get up \\
1 & Mild movement of limbs and trying to get up \\
2 & Slight movement of limbs but not trying to get up \\
3 & Lack of response \\
\hline
\end{tabular}

Table 2. Sedation score in the dogs treated with Zoletil

\begin{tabular}{cl}
\hline \hline Score & \multicolumn{1}{c}{ Condition } \\
\hline 0 & Normal condition \\
1 & Head down, strong palpebral reflex, normal eye position \\
2 & $\begin{array}{l}\text { Head down, moderate palpebral reflex, partial ven- } \\
\text { tromedial eye rotation }\end{array}$ \\
3 & $\begin{array}{l}\text { Head down, no palpebral reflex, partial ventromedial } \\
\text { eye rotation }\end{array}$ \\
\hline
\end{tabular}

determined to be in good condition by a physical examination, complete blood count, and biochemical profile. The dogs were cared for daily in accordance with Chungnam National University Veterinary Medical Teaching Hospital, Korea. Food, but not water, was withheld for at least $12 \mathrm{~h}$ before this experiment. This experiment was approved by Chungnam National University Animal Care and Use Committee.

\section{Methods}

This was a randomized cross-over experimental study. The experiment was performed twice at a 3-week interval. In the experimental group, $0.04 \mathrm{mg} / \mathrm{kg}$ atropine (Atropine sulfate inj $0.5 \mathrm{mg} / \mathrm{mL}$; Jeilpharm, Korea) was injected via a subcutaneous route. An intravenous catheter was placed percutaneously in either the left or right cephalic vein. Zoletil (Zoletil 50; Virbac, France) at a concentration of $10 \mathrm{mg} / \mathrm{kg}$ was injected by the intravenous route. A dose of $0.1 \mathrm{mg}$ dexamethasone (dexamethasone disodium phosphate inj, $5 \mathrm{mg} / \mathrm{mL}$; Huons, Korea) was injected at GV-26 at $20 \mathrm{~min}$ in experimental group and in the quadriceps femoralis in the control group.

Rectal temperature, respiratory rate (breaths/min), heart rate (beats/min), analgesia score, and sedation score were monitored at $0,5,10,20,21,30,40,50,60$, and $90 \mathrm{~min}$. Also, head up time, sternal recumbent time, standing time, and walking time were recorded. Analgesia score was evaluated by pinching of the skin in the inguinal region. Analgesia score and sedation score were evaluated according to Tables 1 and 2. Head up time,

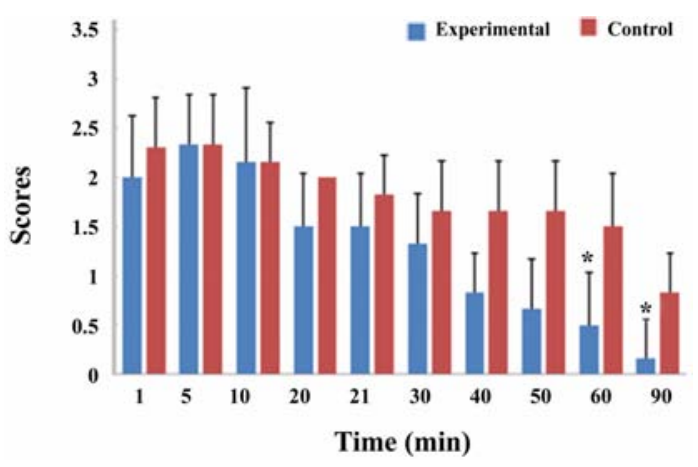

Fig. 1. Comparison of sedation score between Zoletil treated and control groups. ${ }^{*} p<0.05$ : significant statistical difference between both groups.

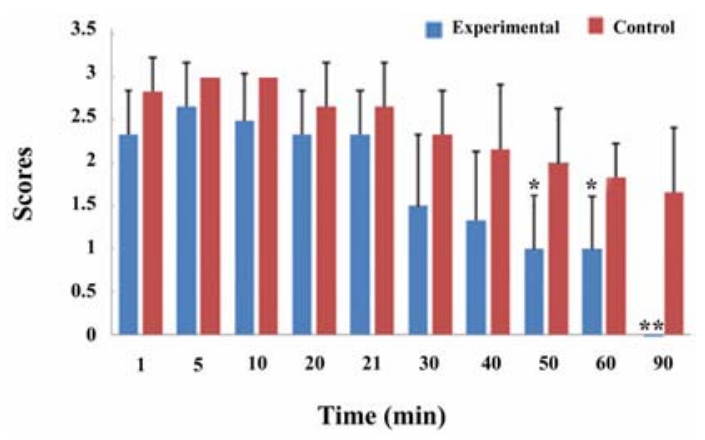

Fig. 2. Comparision of analgesia score between Zoletil treated and control groups. ${ }^{*} p<0.05$ : significant statistical difference between both groups, ${ }^{* *} p<0.01$ : significant statistical difference between both groups.

sternal recumbent time, standing time, and walking time were measured as the times to maintain the particular stable position. In the control group, all procedures were the same as with the experimental group, but $0.1 \mathrm{mg}$ dexamethasone was injected in the quadriceps femoralis instead of in GV-26.

\section{Statistical analysis}

Data was expressed as mean $\pm \mathrm{SD}$. All measured data was analyzed by Mann Whitney U test.

\section{Results}

Rectal temperature, respiratory rate and heart rate were not significant difference in between experimental and control groups (Table 3).

The experimental group recovered earlier from sedation than did the control group of animals (Fig. 1). A 
Table 3. Rectal temperature $\left({ }^{\circ} \mathrm{C}\right)$, heart rate (beat/min) and respiratory time (breath/min) in Zoletil treated and control groups

\begin{tabular}{|c|c|c|c|c|c|c|c|c|c|c|c|}
\hline & & Pre & $5 \mathrm{~min}$ & $10 \mathrm{~min}$ & $20 \mathrm{~min}$ & $21 \mathrm{~min}$ & $30 \mathrm{~min}$ & $40 \mathrm{~min}$ & $50 \mathrm{~min}$ & $60 \mathrm{~min}$ & $90 \mathrm{~min}$ \\
\hline \multirow{2}{*}{$\mathrm{RP}$} & Ex & $\begin{array}{l}38.55 \pm \\
0.39\end{array}$ & $\begin{array}{l}38.13 \pm \\
0.27\end{array}$ & $\begin{array}{l}38.00 \pm \\
0.36\end{array}$ & $\begin{array}{l}37.91 \pm \\
0.42\end{array}$ & $\begin{array}{l}37.73 \pm \\
0.42\end{array}$ & $\begin{array}{l}37.56 \pm \\
0.80\end{array}$ & $\begin{array}{l}37.53 \pm \\
0.36\end{array}$ & $\begin{array}{l}37.40 \pm \\
0.74\end{array}$ & $\begin{array}{l}37.33 \pm \\
0.74\end{array}$ & $\begin{array}{l}37.46 \pm \\
1.01\end{array}$ \\
\hline & Con & $\begin{array}{l}38.55 \pm \\
0.37\end{array}$ & $\begin{array}{l}38.15 \pm \\
0.41\end{array}$ & $\begin{array}{l}37.75 \pm \\
0.50\end{array}$ & $\begin{array}{l}37.65 \pm \\
0.45\end{array}$ & $\begin{array}{l}37.48 \pm \\
0.59\end{array}$ & $\begin{array}{l}37.31 \pm \\
0.54\end{array}$ & $\begin{array}{l}37.06 \pm \\
0.66\end{array}$ & $\begin{array}{l}37.08 \pm \\
0.84\end{array}$ & $\begin{array}{l}37.00 \pm \\
1.05\end{array}$ & $\begin{array}{l}37.26 \pm \\
0.99\end{array}$ \\
\hline \multirow{2}{*}{ HR } & Ex & $\begin{array}{l}128.00 \pm \\
26.04\end{array}$ & $\begin{array}{l}209.16 \pm \\
41.83\end{array}$ & $\begin{array}{l}203.00 \pm \\
23.89\end{array}$ & $\begin{array}{l}169.00 \pm \\
36.82\end{array}$ & $\begin{array}{l}185.66 \pm \\
31.91\end{array}$ & $\begin{array}{l}175.16 \pm \\
33.01\end{array}$ & $\begin{array}{l}173.00 \pm \\
47.15\end{array}$ & $\begin{array}{l}161.66 \pm \\
50.06\end{array}$ & $\begin{array}{l}167.66 \pm \\
51.88\end{array}$ & $\begin{array}{l}158.16 \pm \\
38.71\end{array}$ \\
\hline & Con & $\begin{array}{l}115.00 \pm \\
19.91\end{array}$ & $\begin{array}{l}200.00 \pm \\
33.17\end{array}$ & $\begin{array}{l}186.00 \pm \\
24.89\end{array}$ & $\begin{array}{l}165.66 \pm \\
20.80\end{array}$ & $\begin{array}{l}152.50 \pm \\
27.52\end{array}$ & $\begin{array}{l}168.33 \pm \\
22.49\end{array}$ & $\begin{array}{l}163.83 \pm \\
34.74\end{array}$ & $\begin{array}{l}167.50 \pm \\
32.64\end{array}$ & $\begin{array}{l}145.64 \pm \\
25.12\end{array}$ & $\begin{array}{l}144.00 \pm \\
18.24\end{array}$ \\
\hline \multirow{2}{*}{ RR } & Ex & $\begin{array}{l}28.00 \pm \\
5.65\end{array}$ & $\begin{array}{l}33.33 \pm \\
7.55\end{array}$ & $\begin{array}{l}34.00 \pm \\
6.69\end{array}$ & $\begin{array}{l}41.66 \pm \\
20.05\end{array}$ & $\begin{array}{l}43.83 \pm \\
18.46\end{array}$ & $\begin{array}{l}39.50 \pm \\
20.03\end{array}$ & $\begin{array}{l}41.33 \pm \\
19.33\end{array}$ & $\begin{array}{l}40.00 \pm \\
19.79\end{array}$ & $\begin{array}{l}40.00 \pm \\
19.87\end{array}$ & $\begin{array}{l}32.66 \pm \\
4.71\end{array}$ \\
\hline & Con & $\begin{array}{l}44.00 \pm \\
11.02\end{array}$ & $\begin{array}{l}31.66 \pm \\
12.06\end{array}$ & $\begin{array}{l}42.33 \pm \\
20.09\end{array}$ & $\begin{array}{l}42.66 \pm \\
19.04\end{array}$ & $\begin{array}{l}41.83 \pm \\
19.51\end{array}$ & $\begin{array}{l}50.00 \pm \\
17.79\end{array}$ & $\begin{array}{l}43.66 \pm \\
21.33\end{array}$ & $\begin{array}{l}46.50 \pm \\
20.66\end{array}$ & $\begin{array}{l}41.66 \pm \\
20.56\end{array}$ & $\begin{array}{l}33.66 \pm \\
7.84\end{array}$ \\
\hline
\end{tabular}

RP: rectal temperature, HR: heart rate, RR: respiratory rate, Ex: experimental group, Con: control group.

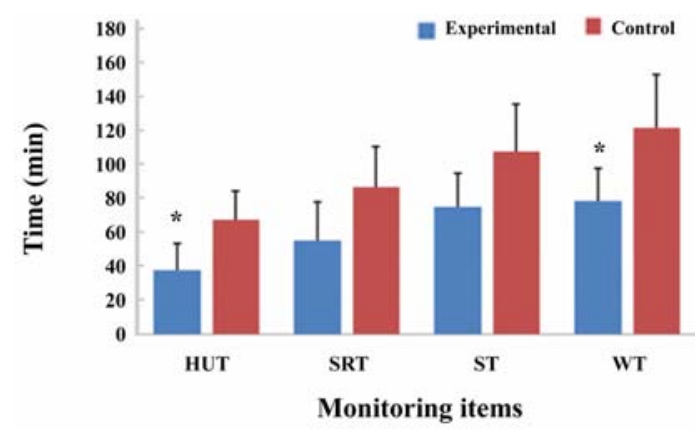

Fig. 3. Comparison of head up time (HUT), sternal recumbent time (SRT), standing time (ST), walking time (WT) between Zoletil treated and control groups. ${ }^{*} p<$ 0.05: significant statistical difference between both groups.

significant difference was evident in the sedation score between groups at 60 and $90 \mathrm{~min}(p<0.05)$. A significant difference was also evident in the analgesia score at 50 and $60 \mathrm{~min}(p<0.05)$. At $90 \mathrm{~min}$, all dogs in the experimental group responded strongly to pain $(p<0.01)$ (Fig. 2).

Head up time, sternal recumbent time, standing time, and walking time was shorter in the experimental group, but the difference from the control group was statistically significant only for head up time and walking time $(p<0.05)$ (Fig. 3).

\section{Discussion}

Intravenously administered tiletamine-zolazepam is a safe and clinically useful in dogs [5]. However, there has been no standard protocol to aid recovery from deep anesthesia.

One of the most commonly used acupoints in the treatment of shock and cardiovascular collapse and arrest is GV-26. Needle acupuncture and electroacupuncture on GV-26 are the most effective means of stimulation [13]. Appropriate stimulation of GV-26 in dogs increases heart rate, stroke volume, and cardiac output and causes pulse pressure changes that are comparable to those induced by injections of epinephrine [4, 13]. In one study, in a dog that had not responded to cardiopulmonary resuscitation with epinephrine, sodium bicarbonate, and fluids, sinus rhythm could be maintained only with continued stimulation of GV-26 [18].

The sympathetic effects of GV-26 have been documented in various species [3, 12, 13, 17, 19]. In a previous study, electroacupuncture on GV-26 was effective for the reversal of the effects of the tiletaminezolazepam anesthesia $20 \mathrm{~min}$ after induction; the increased heart rate, marginal decrease of rectal temperature, and increased respiratory rate helped the dog recover from anesthesia [10].

Aquapuncture, or water puncture, is the injection of saline or distillated water into acupoints. Aquapuncture is one of the methods used for acupuncture treatment. It is a good option for acupuncture in large animals as it requires a shorter period of restraint and uses ordinary materials like a hypodermic needle. The benefits of aquapuncture in the treatment of diverse diseases have been reported $[8,9]$. Presently, no significant differences in rectal temperature and respiratory rate were evident 
between the groups, while significant differences were evident in head up time, walking time, and sedation score at $60 \mathrm{~min}$, and analgesic score at $50 \mathrm{~min}$. The faster head up time and walking time and decreased sedation and analgesic scores in the experimental group are firm evidence that GV-26 aquapuncture with dexamethasone is useful for awareness effects after anesthesia.

We do not fully understand how dexamethasone operates in the awareness mechanism. However, compared to the control group, we can suggest that the effect of awareness is not from dexamethasone but from the acupoint itself. If possible, distilled water or beevenom instead of dexamethasone, could help to better understand the aquapuncture research result. To find out the mechanism of aquapuncture's awareness effect, enzyme-linked immunosorbent assay analysis of catecholamine and epinephrine between groups and other further studies are needed.

\section{Conclusion}

This study was conducted for evaluation of awareness effects by auqapuncture with dexamethasone on GV-26. In this study we found a significant difference between groups in sedation, analgesic score, head up time and walking time. According to the results, we may assume that aquapuncture with dexamethasone on GV-26 can be used for awareness.

\section{References}

1. Batra YK, Negi ON. Therapeutic electroacupuncture in the treatment of cervical spine syndrome. Am J Acupunct 1987, 15, 49-51.

2. Cao QS. A brief view of experimental studies on relationship between the pericardium channel and the heart. J Tradit Chin Med 1989, 9, 48-52.

3. Chang CL, Lee JC, Tseng CC, Chang YH, Cheng JT. Decrease of anesthetic activity by electroacupuncture on Jen-Chung point in rabbits. Neurosci Lett 1995, 202, 93-96.

4. Gürelik M, Karadağ Ö, Polat S, Ozüm Ü, Aslan A, Gürelik B, Göksel HM. The effects of the electrical stimulation of the nasal mucosa on cortical cerebral blood flow in rabbits. Neurosci Lett 2004, 365, 210213.
5. Hellyer P, Muir WW 3rd, Hubbell JA, Sally J. Cardiorespiratory effects of the intravenous administration of tiletamine-zolazepam to dogs. Vet Surg 1989, 18, 160-165.

6. Hubbell JAE, Bednarski RM, Muir WW. Xylazine and tiletamine-zolazepam anesthesia in horses. Am J Vet Res 1989, 50, 737-742.

7. Hwang YC, Jenkins EM. Effect of acupuncture on young pigs with induced enteropathogenic Escherichia coli diarrhea. Am J Vet Res 1988, 49, 1641-1643.

8. Jun HK, Oh HU, Han JW, Lee HH, Jeong SM, Choi SH, Kim MH, Kim DH. Therapeutic effect of beevenom and dexamethasone in dogs with facial nerve paralysis. J Vet Clin 2007, 24, 503-508.

9. Kim DS, Liu JZ, Lee JY, Kim MC, Shin ST, Kim DH. The anti-emetic effect of acupuncture and aquaacupuncture at PC-6 and BL-21 on the emesis by xylazine in dogs. Korean J Vet Res 2005, 45, 399-403.

10. Kim KI, Yun YM, Lee JY, Kang TY, Kim GH, Cheong JT, Lee KK. The reverse effects by electroacupunture on Jun Chung (GV-26) in dogs. J Vet Clin 2003, 20, 312-316.

11. Lagutchik MS, Januszkiewicz AJ, Dodd KT, Martin DG. Cardiopulmonary effects of a tiletamine-zolazepam combination in sheep. Am J Vet Res 1991, 52, 14411447.

12. Lee DC, Lee MO, Clifford DH. Cardiovascular effects of acupuncture in anesthetized dogs. Am J Chin Med (Gard City N Y) 1974, 2, 271-282.

13. Lee DC, Lee MO, Clifford DH, Morris LE. The autonomic effects of acupuncture and analgesic drugs on the cardiovascular system. Am J Acupunct 1982, 10, 5-30.

14. Lin HC. Dissociative anesthesics. In: Thurmon JC, Tranquilli WJ, Benson GJ (eds.). Lumb and Jone's Veterinary Anesthesia. 3rd ed. pp. 241-296, Williams \& Wilkins, Baltimore, 1996.

15. Massolo A, Sforzi A, Lovari S. Chemical immobilization of crested porcupines with tiletamine $\mathrm{HCl}$ and Zolazepam $\mathrm{HCl}$ (Zoletil) under field conditions. J Wildl Dis 2003, 39, 727-731.

16. Radzievsky SA, Lebedeva OD, Fisenko LA, Majskaja SA. Function of myocardial contraction and relaxation in essential hypertension in dynamics of acupuncture therapy. Am J Chin Med 1989, 17, 111117.

17. Ruocco I, Cuello AC, Parent A, Ribeiro-Da-Silva A. 
Skin blood vessels are simultaneously innervated by sensory, sympathetic, and parasympathetic fibers. J Comp Neurol 2002, 448, 323-336.

18. Schoen AM. Electrocardiographic recording during dry needle stimulation of GV-26 following cardiac arrest. Int J Vet Acupunct 1990, 1, 21-23.

19. Still J. Research in Veterinary Acupuncture. pp. 57-64,
Belgian Veterinary Acupuncture Society, Brussels, 1991. 20. Syuu Y, Matsubara H, Kiyooka T, Hosogi S, Mohri S, Araki J, Ohe T, Suga H. Cardiovascular beneficial effects of electroacupuncture at Neiguan (PC-6) acupoint in anesthetized open-chest dog. Jpn J Physiol 2001, 51, 231-238. 